Original

\title{
Estimation of the collective ionizing dose in the Portuguese population for the years 2011 and 2012, due to nuclear medicine exams
}

\author{
F. Costa ${ }^{\mathrm{a}, *}$, P. Teles ${ }^{\mathrm{a}}$, A. Nogueira ${ }^{\mathrm{b}}$, A. Barreto ${ }^{c}$, A.I. Santos ${ }^{c}$, A. Carvalho ${ }^{\mathrm{d}}$, B. Martins ${ }^{\mathrm{e}, \mathrm{f}}$, C. Oliveira ${ }^{\mathrm{e}}$, \\ C. Gaspar ${ }^{\mathrm{g}}$, C. Barros ${ }^{\mathrm{h}}$, D. Neves ${ }^{\mathrm{i}}$, D. Costa ${ }^{\mathrm{e}}$, E. Rodrigues ${ }^{\mathrm{j}}$, F. Godinho ${ }^{\mathrm{k}, \mathrm{l}}$, F. Alves ${ }^{\mathrm{m}, \mathrm{n}}$, G. Cardoso ${ }^{\mathrm{c}}$, \\ G. Cantinho ${ }^{\mathrm{k}, 1}$, I. Conde ${ }^{\mathrm{o}}$, J. Vale ${ }^{\mathrm{p}}$, J. Santos ${ }^{\mathrm{q}}$, J. Isidoro ${ }^{\mathrm{r}}$, J. Pereira ${ }^{\mathrm{d}}$, L. Salgado ${ }^{\mathrm{s}}$, M. Rézio ${ }^{\mathrm{s}, \mathrm{t}}$,

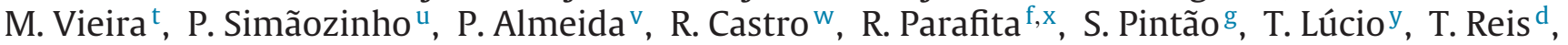 \\ P. Vaz ${ }^{\mathrm{a}}$
}

a Instituto Tecnológico e Nuclear, Campus Tecnológico e Nuclear, Universidade Técnica de Lisboa, Estrada Nacional 10 (km 139,7), 2695-066 Bobadela LRS, Portugal

${ }^{\mathrm{b}}$ NuclearMed, HPA - Hospital Particular de Almada, Rua Manuel Febrero, 85, 2800-455 Almada, Portugal

${ }^{c}$ Hospital Garcia de Orta, Av. Torrado da Silva, 2801-951 Almada, Portugal

${ }^{d}$ Centro Hospitalar S. João, Alameda Prof. Hernâni Monteiro, 4200-319 Porto, Portugal

e Fundação Champalimaud, Av. Brasília, 1400-038 Lisboa, Portugal

${ }^{\mathrm{f}}$ Medical Consult, SA, Campo Grande, $n^{\circ}$ 56-8 A, 1700-093 Lisboa, Portugal

${ }^{g}$ Hospital de Santa Cruz, Centro Hospitalar de Lisboa Ocidental, Avenida Prof. Dr. Reinaldo dos Santos, 2790-134 Carnaxide, Portugal

${ }^{\mathrm{h}}$ Instituto Português de Oncologia de Coimbra, Francisco Gentil, EPE, Av. Bissaya Barreto, n॰ 98, 3000-075 Coimbra, Portugal

i Diaton, Unidade de Diagnóstico de Leiria, Rua das Olhalvas, Pousos, 2410-197 Leiria, Portugal

j Quadrantes - Unidade de Radioterapia do Funchal, Rua de Santa Rita, S. Martinho, 9000-238 Funchal, Portugal

k Atomedical, Rua Helena Félix, 11 D, 1600-121 Lisboa, Portugal

${ }^{1}$ Faculdade de Medicina da Universidade de Lisboa, Av. Prof. Egas Moniz, Hospital de Santa Maria, Cidade Universitária, 1649-028 Lisboa, Portugal

m ICNAS - Instituto de Ciências Nucleares Aplicadas à Saúde, Azinhaga de Santa Comba, 3000-548 Coimbra, Portugal

n Escola Superior de Tecnologia da Saúde de Coimbra, Rua 5 de Outubro, Apartado, 70063046-854 Coimbra, Portugal

${ }^{\circ}$ Clínica Quadrantes Miraflores, Av. General Norton de Matos, 71 R/C Miraflores, 1495-068 Algés, Portugal

p HPP - Medicina Molecular, Av. da Boavista, 119 4050-115 Porto, Portugal

${ }^{q}$ Instituto Português de Oncologia do Porto, Francisco Gentil, EPE, Rua Dr. António Bernardino de Almeida, 4200-072 Porto, Portugal

${ }^{\mathrm{r}}$ Hospitais da Universidade de Coimbra, Avenida Bissaya Barreto, 3000-076 Coimbra, Portugal

s Instituto Português de Oncologia de Lisboa, Francisco Gentil, EPE, R. Prof. Lima Basto, 1099-023 Lisboa, Portugal

${ }^{\mathrm{t}}$ Hospital da Luz, Avenida Lusíada, 100, 1500-650 Lisboa, Portugal

u Administração Regional de Saúde - Algarve, Largo de São Pedro, ${ }^{\circ}$ 15, 8000-145 Faro, Portugal

` Instituto de Biofísica e Engenharia Biomédica, Faculdade de Ciências da Universidade de Lisboa, Campo Grande, 1749-016 Lisboa, Portugal

${ }^{w}$ Hospital Geral de Santo António, Largo Prof. Abel Salazar - Edifício Neoclássico, 4099-001 Porto, Portugal

x Hospital Cuf Descobertas, Rua Mário Botas, Parque das Nações, 1998-018 Lisboa, Portugal

${ }^{y}$ Hospital Beatriz Ângelo, Avenida Carlos Teixeira, 3, 2674-514 Loures, Portugal

\section{A R T I C L E I N F O}

\section{Article history:}

Received 21 January 2014

Accepted 31 March 2014

Available online 17 June 2014

\section{Keywords:}

Nuclear medicine

Portuguese population

Collective dose

Effective dose

Dose Datamed II

\begin{abstract}
A B S T R A C T
Objectives: In 2009-2010 a Portuguese consortium was created to implement the methodologies proposed by the Dose Datamed II (DDM2) project, aiming to collect data from diagnostic X-ray and nuclear medicine (NM) procedures, in order to determine the most frequently prescribed exams and the associated ionizing radiation doses for the Portuguese population. The current study is the continuation of this work, although it focuses only on NM exams for the years 2011 and 2012.

Material and methods: The annual frequency of each of the 28 selected NM exams and the average administered activity per procedure was obtained by means of a nationwide survey sent to the $35 \mathrm{NM}$ centres in Portugal.

Results: The results show a reduction of the number of cardiac exams performed in the last two years compared with 2010, leading to a reduction of the annual average effective dose of Portuguese population due to $\mathrm{NM}$ exams from $0.08 \mathrm{mSv} \pm 0.017 \mathrm{mSv} /$ caput to $0.059 \pm 0.011 \mathrm{mSv} /$ caput in 2011 and $0.054 \pm 0.011 \mathrm{mSv} /$ caput in 2012. Portuguese total annual average collective effective dose due to medical procedures was estimated to be $625.6 \pm 110.9$ manSv in 2011 and $565.1 \pm 117.3$ manSv in 2012, a reduction in comparison with $2010(840.3 \pm 183.8$ manSv).

Conclusions: The most frequent exams and the ones that contributed the most for total population dose were the cardiac and bone exams, although a decrease observed in 2011 and in 2012 was verified. The authors intend to perform this study periodically to identify trends in the annual Portuguese average effective dose and to help to raise awareness about the potential dose optimization.
\end{abstract}

(C) 2014 Elsevier España, S.L.U. and SEMNIM. All rights reserved.

\footnotetext{
* Corresponding author.

E-mail address: filipa.apbcosta@gmail.com (F. Costa).
} 


\section{Estimación de la dosis colectiva en la población portuguesa de los años 2011 y} 2012, debido a los exámenes de medicina nuclear

Palabras clave:

Medicina Nuclear

Población Portuguesa

Dosis colectiva

Dosis efectiva

Dose Datamed II

\section{R E S U M E N}

Objetivo: En 2009 y 2010 un consorcio portugués ha sido creado para implementar las metodologías propuestas por el proyecto europeo Datamed II (DDM2), con el objetivo de coleccionar datos de procedimientos de radiología de diagnóstico y medicina nuclear (MN) más frecuentes, así como la dosis asociada en la población portuguesa. Este estudio es una continuación del trabajo, que se centrará en los datos de MN para los años de 2011 y 2012.

Material y Métodos: La frecuencia anual de cada uno de los 28 exámenes de MN seleccionados y la actividad media administrada por procedimiento se obtuvieron a través de una encuesta enviada a los 35 departamentos de MN en Portugal.

Resultados: Los resultados muestran una reducción drástica en el número de procedimientos cardiacos en los últimos dos años, lo que tiene como consecuencia una reducción de la dosis efectiva anual en la población portuguesa derivado de procedimientos de MN de 0,08mSv $\pm 0,017 \mathrm{mSv} /$ caput en 2010, a $0,059 \pm 0,011 \mathrm{mSv} /$ caput in 2011 y $0,054 \pm 0,011 \mathrm{mSv} /$ caput in 2012. La dosis efectiva colectiva media en la población portuguesa es estimada en 625.6 \pm 110.9 manSv en 2011, y 565.1 \pm 117.3 manSv en 2012. Conclusiones: Los exámenes cardiacos y óseos fueron más frecuentes y los que más contribuyeron para la dosis total de la población, aunque se verificó una disminución en 2011 y en 2012. Los autores de este trabajo pretenden realizar este tipo de estudios periódicamente para identificar tendencias en los diferentes procedimientos de MN y ayudar a aumentar la conciencia de los profesionales de MN sobre este asunto.

(c) 2014 Elsevier España, S.L.U. y SEMNIM. Todos los derechos reservados.

\section{Introduction}

The use of ionizing radiation for medical purposes has increased over the past decades, contributing to over $95 \%$ of man-made radiation exposure. ${ }^{1}$ Even if image quality improved, allowing for more accurate diagnoses, a significant increase of the dose delivered to each patient also occurred. Procedures such as computed tomography $(\mathrm{CT})$, interventional procedures, and cardiac nuclear medicine are thought to be the main contributors to such an increase in exposure. International organizations such as the United Nations Scientific Committee on the Effects of Atomic Radiation (UNSCEAR) and the European Commission (EC) published several reports in which increased values of worldwide collective dose are presented. ${ }^{2,3}$ The EC has concerns about the wide differences between the reported results of population dose estimations from different European countries with similar healthcare levels, which may be due to the absence of a common European methodology. This led to the creation of a multinational European project, in 2004, the Dose Datamed I (DDM1), in which a group of countries with tradition in conducting studies of population exposure participated, with the aim of finding a common methodology. Based on the experience of 10 European countries, Radiation Protection no. 154 was created. ${ }^{4}$ This document provides practical guidance to create a harmonized system for assessing patient doses in Member States in order to compare national population doses in the future. Guidance is provided to assess dose due to medical X-ray imaging and nuclear medicine (NM) procedures. It should be noted that there has been a long history of carrying out periodic reviews of the population exposure in most countries participating in DDM I, in contrast with what happens in Portugal.

In 2009-2010 the European Commission financed the project Dose Datamed II (DDM2), ${ }^{5}$ a follow-up study of DDM1, also called "Study on European Population Doses From Medical Exposure", aiming to collect data from diagnostic X-ray and nuclear medicine procedures in order to determine the most frequently prescribed exams and the associated collective doses in the European population. ${ }^{6}$ Portugal, together with other 35 countries participated in this study. ${ }^{7}$ For such, a Portuguese consortium was created, to potentiate the implementation of the methodologies proposed by DDM2. ${ }^{8}$ This led to an estimation of the dose to the Portuguese Population of $\sim 1 \mathrm{mSv}$ caput $^{-1}$ for the year 2010 and, of particular interest to this work, of $0.080 \pm 0.0017 \mathrm{mSv} /$ caput due to nuclear medicine examinations. ${ }^{9}$

The current study aims to be both a continuation and an improvement of the previous work, focusing only on the population doses to nuclear medicine procedures, for the years 2011 and 2012, and comparing them with the results obtained in 2010. Radiation doses due to radiodiagnostic exams will be analyzed elsewhere. The most frequent nuclear medicine exams and those that contribute the most for the annual collective dose were assessed. The Portuguese results are also compared with those available for other European Countries. Finally, the yearly trends of population dose and annual frequencies of different nuclear medicine exams were also analyzed.

\section{Material and methods}

The methodology used in this study was based on the report Radiation Protection 154 (RP154). For nuclear medicine practices, the RP154 recommends the implementation of a nationwide survey to the extant nuclear medicine centres. ${ }^{4}$ A table with the most common nuclear medicine procedures is proposed in the report, involving the most utilized radionuclides divided in six major types of diagnostic exams (bone, heart, thyroid, lung, kidney and the remainders). This consists of 28 NM examinations (procedure, radionuclide and chemical form) as presented in Table 1.

A nationwide survey was sent to all 35 nuclear medicine centres in Portugal. The centres were invited to fill in a file with the annual frequency of each exam, as well as the average administered activity per procedure. In addition, each NM centre could include a list of exams they considered relevant (high number of patients performing the exam or high administered activity). For the NM centres which had this information available, only data from adults (>18 yrs) were included. In Portugal, a total of 34 NM departments were identified in 2011 and 35 in 2012, unlike the 32 centres in 2010. The use of different radionuclides highly affects the effective dose per examination, so it is important to guarantee the same radionuclide is being used for the same procedure.

Of the 34 identified centres in 2011, four did not possess any statistical data and the other six did not reply. In 2012 from the universe of 35 centres, four did not possess any statistical data and 
Table 1

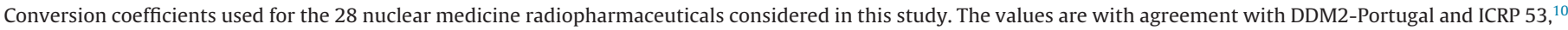
$80^{11}$ and $106 .^{12}$

\begin{tabular}{|c|c|c|}
\hline Nuclear medicine procedure & Radionuclide and chemical form & Conversion coefficient (mSv/MBq) \\
\hline 1. Bone imaging & ${ }^{99 \mathrm{~m}} \mathrm{Tc}-$ phosphates and phosphonates & $5.70 \times 10^{-3}$ \\
\hline 2. Myocardial perfusion with thallium & ${ }^{201} \mathrm{Tl}$ - chloride & $2.20 \times 10^{-1}$ \\
\hline 3. Myocardial perfusion with Tetrofosmin (rest) & ${ }^{99 \mathrm{~m}} \mathrm{Tc}$ - tetrofosmin & $7.60 \times 10^{-3}$ \\
\hline 4. Myocardial perfusion with Tetrofosmin (exercise) & $99 \mathrm{~m} \mathrm{Tc}$ - tetrofosmin & $7.00 \times 10^{-3}$ \\
\hline 5. Myocardial perfusion with MIBI (rest) & ${ }^{99 \mathrm{~m}} \mathrm{Tc}-\mathrm{MIBI}$ & $9.00 \times 10^{-3}$ \\
\hline 6. Myocardial perfusion with MIBI (exercise) & ${ }^{99 m} \mathrm{Tc}-\mathrm{MIBI}$ & $7.90 \times 10^{-3}$ \\
\hline 7. Myocardial perfusion (PET) & ${ }^{18} \mathrm{~F}-\mathrm{FDG}$ & $1.90 \times 10^{-2}$ \\
\hline 8. Myocardial perfusion (PET) & ${ }^{15} \mathrm{O}-\mathrm{H}_{2} \mathrm{O}$ & $9.30 \times 10^{-4}$ \\
\hline 9. Positron emission tomography & ${ }^{18} \mathrm{~F}-\mathrm{FDG}$ & $1.90 \times 10^{-2}$ \\
\hline 10. Positron emission tomography + diagnostic CT & ${ }^{18} \mathrm{~F}-\mathrm{FDG}$ & $1.90 \times 10^{-2}$ \\
\hline 11. Thyroid metastases (after ablation, uptake $0 \%$ ) & ${ }^{131} \mathrm{I}$ - iodide & $6.10 \times 10^{-2}$ \\
\hline 12. Thyroid imaging (oral uptake, no blocking) & ${ }^{99 \mathrm{~m}} \mathrm{Tc}$ - pertechnetate & $1.40 \times 10^{-2}$ \\
\hline 13. Thyroid imaging ( $35 \%$ thyroid uptake) & ${ }^{123} \mathrm{I}$ - iodide & $2.20 \times 10^{-2}$ \\
\hline 14. MUGA, cardiac blood pool, cardiac blood flow (equilibrium) & ${ }^{99 m}$ Tc - DTPA & $4.90 \times 10^{-3}$ \\
\hline 15. MUGA, cardiac blood pool, cardiac blood flow (equilibrium) & ${ }^{99 \mathrm{~m}} \mathrm{Tc}-\mathrm{Tc}$-labelled erythrocytes & $7.00 \times 10^{-3}$ \\
\hline 16. Dopamine transporter imaging (parkinsonism) & ${ }^{123} \mathrm{I}-\beta$ CIT & $5.00 \times 10^{-2}$ \\
\hline 17. Dopamine transporter imaging (parkinsonism) & ${ }^{123} \mathrm{I}$ - ioflupane (DatScan) & $2.40 \times 10^{-2}$ \\
\hline 18. Lung perfusion & ${ }^{99 \mathrm{~m}} \mathrm{Tc}-\mathrm{MAA}$ & $1.10 \times 10^{-2}$ \\
\hline 19. Neuroendocrine tumours/somatostatin receptors imaging & ${ }^{111}$ In - pentetreotide (OctreoScan) & $1.20 \times 10^{-1}$ \\
\hline 20. Renal imaging & ${ }^{99 m} \mathrm{Tc}-\mathrm{DMSA}$ & $8.80 \times 10^{-3}$ \\
\hline 21. Renal imaging & ${ }^{99 \mathrm{~m}} \mathrm{Tc}-\mathrm{MAG} 3$ & $7.00 \times 10^{-3}$ \\
\hline 22. Renal imaging & ${ }^{99 \mathrm{~m}} \mathrm{Tc}-\mathrm{DTPA}$ & $4.90 \times 10^{-3}$ \\
\hline 23. Parathyroid imaging & ${ }^{99 \mathrm{~m}} \mathrm{Tc}-\mathrm{MIBI}$ & $9.00 \times 10^{-3}$ \\
\hline 24. Cerebral blood flow & ${ }^{99 \mathrm{~m}} \mathrm{Tc}$ - exametazine (HMPAO) & $9.30 \times 10^{-3}$ \\
\hline 25. Cerebral blood flow & ${ }^{99 \mathrm{~m}} \mathrm{Tc}-\mathrm{ECD}$ (neurolite) & $2.20 \times 10^{-3}$ \\
\hline 26. Infection/inflammation imaging & ${ }^{67} \mathrm{Ga}$ - gallium citrate & $1.00 \times 10^{-1}$ \\
\hline 27. Infection/inflammation imaging & ${ }^{99 \mathrm{~m}} \mathrm{Tc}-\mathrm{Tc}$-labelled leucocytes & $1.10 \times 10^{-2}$ \\
\hline 28. Infection/inflammation imaging & ${ }^{99 \mathrm{~m}} \mathrm{Tc}-$ monoclonal antibody (LeucoScan) & $8.00 \times 10^{-3}$ \\
\hline
\end{tabular}

six did not reply, giving 25 answers to the survey. This gives a participation ratio of answers to the survey of $80 \%$ and $81 \%$ for 2011 and 2012, respectively. This is an improvement in comparison with the $73 \%$ answer ratio in 2010 ( 19 NM centres answered the survey, seven had no statistical data and six did not reply).

The effective dose for each exam and the collective effective dose were calculated. In order to do that, the average weighted activity for $\left(A_{\text {avg }}(x)\right)$ each nuclear medicine procedure $x$ was calculated,

$A_{\text {avg }}(x)=\frac{\sum_{i=1}^{n} A_{i} \text { freq }_{i}(x)}{\sum_{i=1}^{n} \text { freq }_{i}(x)}$

where $A_{t}$ is the average activity as reported by NM centre $i$ and nuclear medicine procedure $x$. The total number of participant centres is given by $n$ and freq $_{i}(x)$ represents the frequency of each examination $x$ in centre $i$. The dose per caput for each nuclear medicine procedure is determined as follows:

$\frac{D}{\text { caput }}(x)=\frac{A_{\text {avg }}(x) \cdot e_{x} \cdot \sum_{i=1}^{n} \text { freq }_{i}(x)}{\text { population }}$

$e_{x}$ is the effective dose [] taken from the International Commission on Radiological Protection (ICRP), the same one applied in the previous study of DDM2 in Portugal. ${ }^{9}$ The variable population refers to the total population of Portugal (10,555,853 inhabitants). ${ }^{13}$

The total dose per caput due to all NM examination is given by the sum of each dose determined for each procedure. A linear correction factor was calculated for 2011 and 2012 in order to extrapolate the obtained values based on the positive response ratio. This value is $1.25(=1 / 0.80)$ for 2011 and $1.23(=1 / 0.81)$ for 2012.

A questionnaire was also sent to the 25 nuclear medicine participant centres in order to get more information about each centre, to understand the difficulties experienced by healthcare professionals in dose assessment and to assess opinions in some important matters such as the creation of Portuguese guidelines. The questionnaire sent to the nuclear medicine centres consisted of the following five questions:
- Which protocol is used at your centre to determine the activity administered in a patient?

- If national guidelines were established in order to standardize the protocols used in medical services, would your centre follow them?

- Do you usually register the activity values when injecting a patient, or just the referred protocol value?

- How easily did you separate the activity values and the number of exams for adult patients from paediatric patients, if this is possible in your centre?

- In case a separation of the sent data by the patient's age and sex would be requested, would it be easy for you to do it?

\section{Results}

Population exposure in Portugal for the years 2010, 2011 and 2012

\section{Frequencies}

In this work, data for the years 2011 and 2012 were obtained and compared with the one obtained for 2010. Data showed that 17.97 NM procedures per 1000 population were performed in Portugal in 2010, 13.34 in 2011 and 11.60 in 2012. In Fig. 1 a graph is displayed showing the trends in the annual frequency of nuclear medicine exams performed from 2010 to 2012. A reduction on the number of total nuclear medicine exams and cardiac exams performed in 2011 compared with 2010 is observed. A tiny decrease on the total and cardiac exams performed is also observed in 2012 in relation to 2011.

\section{Cardiac exams and their influence in the results}

The cardiac exams considered in this work are: (i) myocardial perfusion with tetrofosmin (exercise and rest), (ii) myocardial perfusion with MIBI (exercise and rest), (iii) myocardial perfusion with thallium, (iv) MUGA - cardiac blood pool, cardiac blood flow (equilibrium), and (v) positron emission tomography (PET) - cardiac study (metabolism and perfusion). In Fig. 2 the annual frequency of each cardiac exam presented in this study is shown, except for 


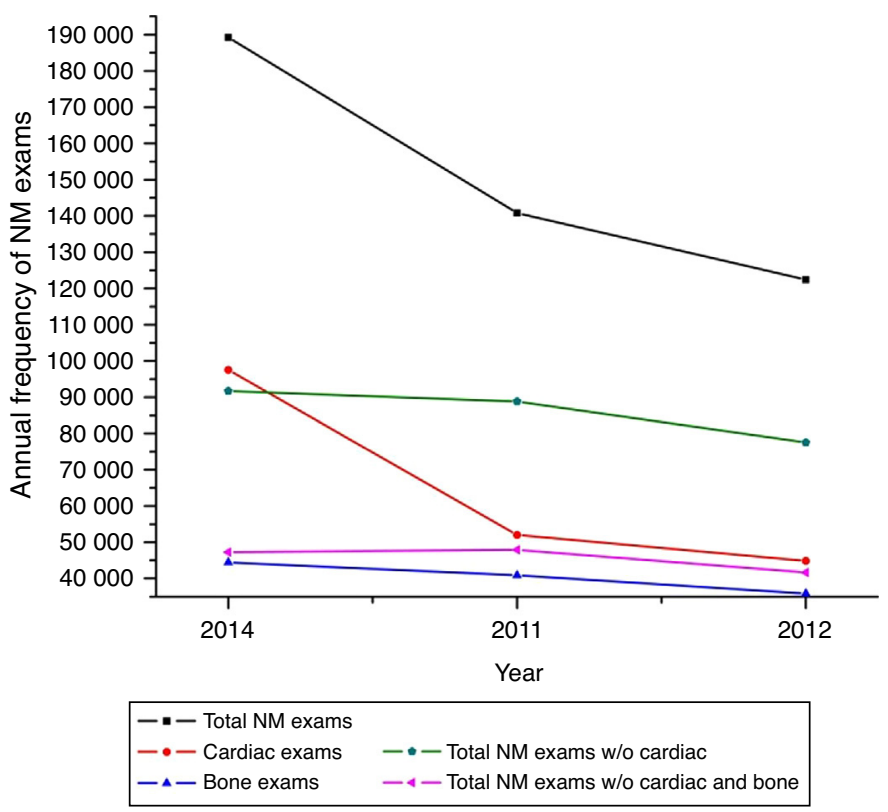

Fig. 1. Total annual frequency of NM exams. Influence of cardiac and bone examinations on the total annual frequency of NM exams.

PET since there is no relevant statistical data. A sharp decrease in the annual frequency of myocardial perfusion tetrofosmin and MIBI examination is observed in the last two years compared with 2010. The MUGA - cardiac blood pool examination did not influence the decrease of annual frequency, as its frequency remains constant along the three years. Finally, myocardium perfusion imaging with thallium displays a constant and a low number of exams performed annually.

\section{Collective dose}

Applying the conversion factors, as given in Table 1 , the Portuguese total annual average collective effective dose due to diagnostic nuclear medicine exams was estimated to be $625.6 \pm 110.9$ manSv $(0.059 \pm 0.011 \mathrm{mSv}$ per caput $)$ in 2011 and $565.1 \pm 117.3$ manSv $(0.054 \pm 0.011 \mathrm{mSv})$ in 2012 . The dose values decreased considerably relative to the value estimated for 2010 , $840.3 \pm 183.8 \mathrm{manSv}(0.080 \pm 0.017 \mathrm{mSv}$ per caput $)$. The uncertainties were calculated using the weighted standards deviation of the reported activities for each centre. Expanding the uncertainty for each determined collective dose per exam, the uncertainty in the total collective dose was estimated. Table 2 shows that the collective dose in 2010 due to cardiac exams is more than twice the value of collective dose calculated in 2012. The values of total collective dose without cardiac exams are very similar amongst the three years. Finally, the total collective dose is inferior in 2012 also due to the reduced value of bone imaging examinations.

\section{Exam types}

Each of the six different examination groups' contribution (bone, heart, thyroid, lung, kidney and remainder) to the annual frequencies and to the total collective dose from nuclear medicine procedures is shown in Fig. 3. Cardiac procedures are the most frequently acquired nuclear medicine exams and the ones that contribute the most for the total collective dose received by the Portuguese population, although this contribution is diminishing. Heart and bone exams together correspond to approximately $70 \%$ of the total amount of nuclear medicine exams performed during the three years studied. In 2010 both categories contributed to $84 \%$ of the total annual dose due to NM procedures, while in 2011 and 2012 that contribution was $70 \%$ and $68 \%$, respectively.

The four exams that contributed the most to the high value of annual collective dose shown in the remainder exams in 2011 and 2012 are neuroendocrine tumours/somatostatin receptors imaging, infection/inflammation imaging with gallium, whole body PET and whole body PET + CT. In 2010 those were the same exams that contributed the most for the total value of collective effective dose, amongst the remainder exams, except the contribution of somatostatin receptors imaging which was lower (Fig. 4).

\section{TOP 10 of the nuclear medicine exams}

In 2010, the 10 nuclear medicine exams that contributed the most to the total collective effective dose were identified in the DDM2-Portugal study (TOP 10). The contribution of each exam is shown in Fig. 5 for 2010, 2011 and 2012. In 2011 and 2012 the 10 exams that contributed the most to the total collective effective dose were different than the ones found in 2010. In Table 3 is shown the TOP 10 exams with higher contribution to the collective effective dose for the years 2010, 2011 and 2012. In 2011, myocardium perfusion with thallium contributed $1.7 \%$ to the total collective effective dose, which is no longer on the top 10 exams. Neuroendocrine tumours/somatostatin receptors imaging contributed more to the total collective effective dose in 2011 (3.2\%). In 2012, the contribution of myocardium perfusion examinations with thallium decreased even further to $0.2 \%$, and whole body PET + CT

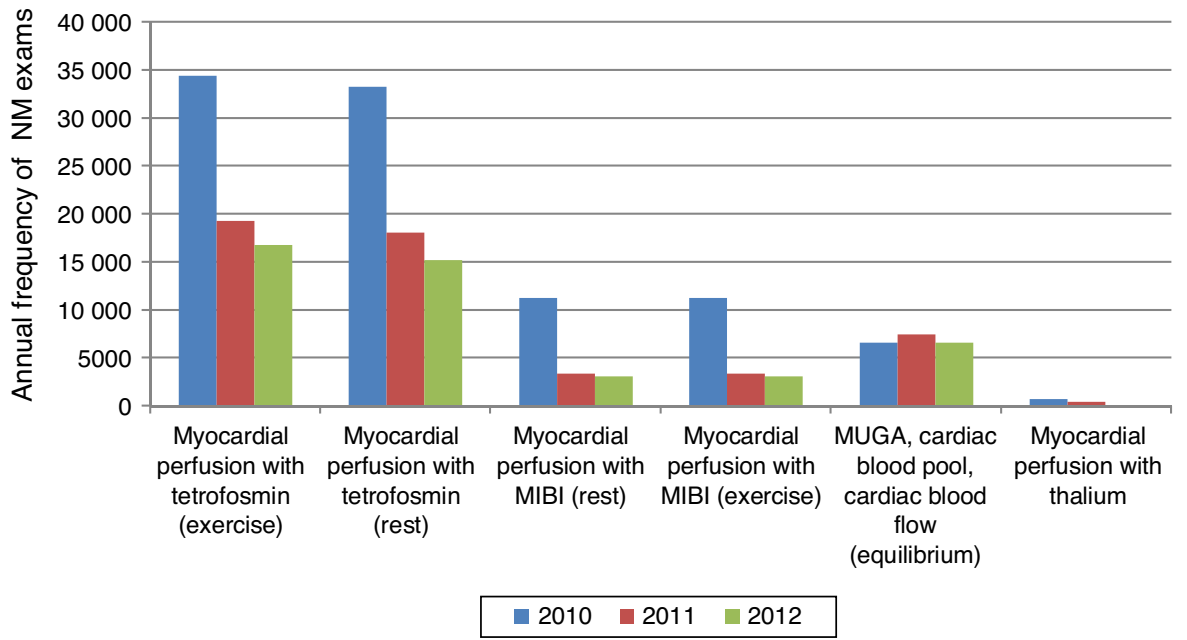

Fig. 2. Annual frequency of six nuclear medicine exams in the years 2010, 2011 and 2012. 
Table 2

Annual collective dose due to all nuclear medicine exams and only cardiac and bone nuclear medicine exams.

\begin{tabular}{|c|c|c|c|c|c|}
\hline Year & $\begin{array}{l}\text { Total collective } \\
\text { dose (manSv) }\end{array}$ & $\begin{array}{l}\text { Collective dose due } \\
\text { to cardiac exams } \\
\text { (manSv) }\end{array}$ & $\begin{array}{l}\text { Collective dose due } \\
\text { to bone exams } \\
\text { (manSv) }\end{array}$ & $\begin{array}{l}\text { Total collective } \\
\text { dose w/o cardiac } \\
\text { exams (manSv) }\end{array}$ & $\begin{array}{l}\text { Total collective dose w/o } \\
\text { cardiac and bone exams } \\
(\mathrm{manSv})\end{array}$ \\
\hline 2010 & 840.3 & 453.7 & 183.28 & 372.5 & 189.2 \\
\hline 2011 & 625.6 & 248.3 & 178.99 & 377.4 & 198.4 \\
\hline 2012 & 565.1 & 219.3 & 156.80 & 343.7 & 186.9 \\
\hline
\end{tabular}
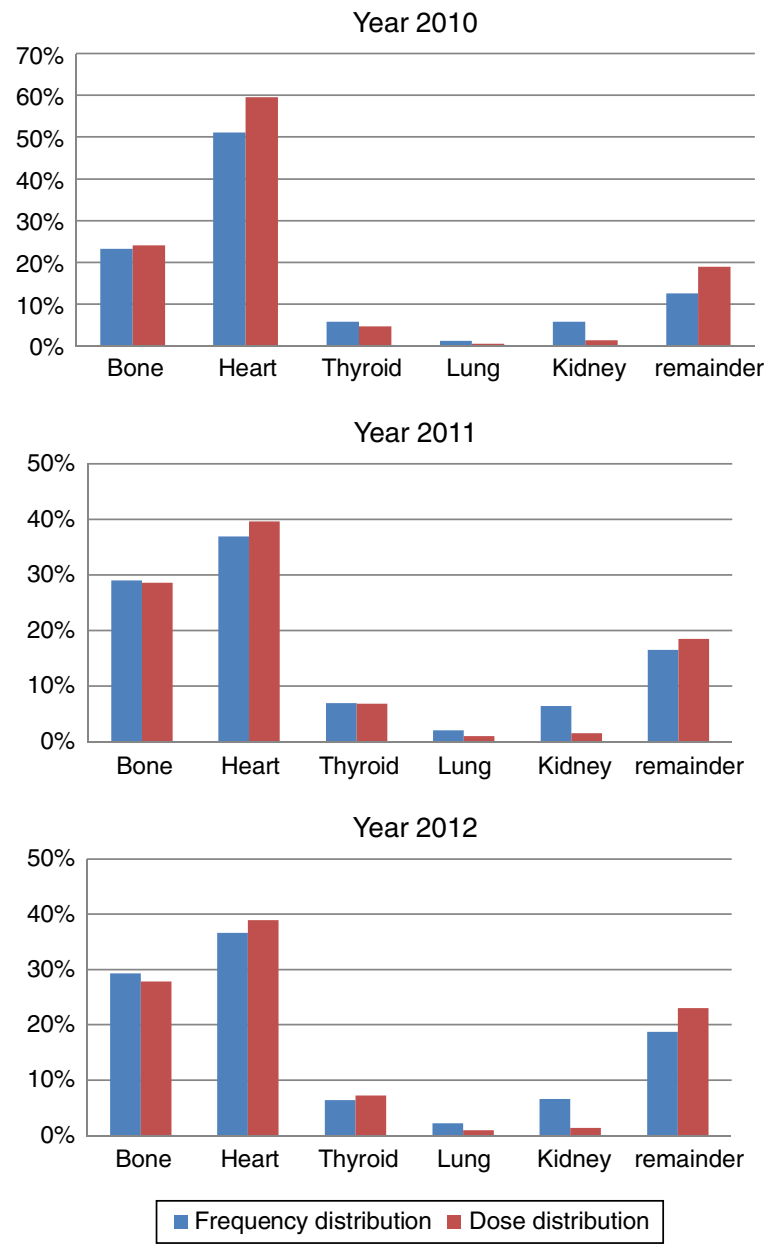

Fig. 3. Relative contribution (\%) of six nuclear medicine groups to the total frequency and total population dose of nuclear medicine examinations.

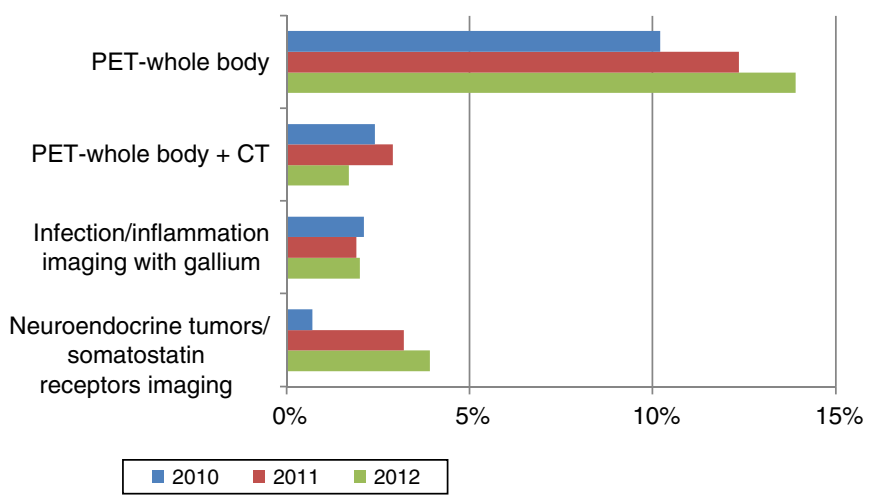

Fig. 4. Relative contribution (\%) of remainder exams to the total collective effective dose.
Table 3

TOP 10 exams for the year 2010, 2011 and 2012.

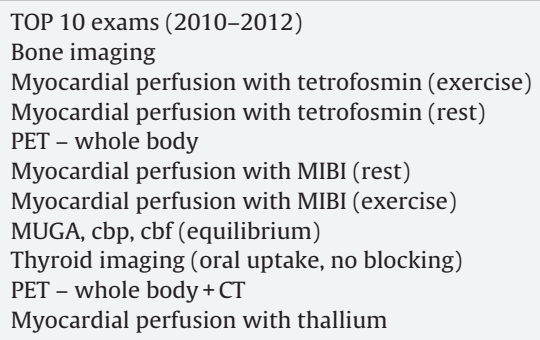

decreased to $1.7 \%$, being no longer in the top 10 exams. Neuroendocrine tumours/somatostatin receptors imaging and thyroid metastases (after ablation, uptake $0 \%$ ) contributed more to the population's exposure with $3.94 \%$ and $2.9 \%$ respectively, more than the aforementioned examinations.

\section{Portugal and other European countries}

The relative contribution of NM procedures to the collective effective dose (manSv) was calculated for the 35 countries that participated in DDM2. ${ }^{6}$ The report suggested a group of top 7 exams, selecting the highest examinations' contributors to the collective effective dose in all DDM2 countries. These top 7 exams are in fact 11 examinations. DDM2 report grouped the myocardial perfusion with MIBI examination (rest and stress) with myocardial perfusion with tetrofosmin (rest and stress) in only one examination called heart exam with ${ }^{99 \mathrm{~m}} \mathrm{Tc}$, while whole body PET + CT and PET were also grouped in only one exam. The minimum, maximum and median values were estimated for the identified exams. The same calculations were performed to study the Portuguese reality based on the collective dose data for the year 2010, 2011 and 2012. The results obtained for Portugal and DDM2 countries are shown in Fig. 6. The rest and stress myocardial perfusion exams were grouped, since no information was available in separate for DDM2 participant countries. ${ }^{6}$ The bars represent the minimum and maximum values identified for all countries participating in DDM2 and the Portuguese results between 2010 and 2012. The results differ greatly between the Portugal and the remainder DDM2 countries, particularly regarding bone imaging and myocardium perfusion with MIBI.

For the same 11 examinations in consideration, now separating the rest from the stress myocardial perfusions exams, the dose per procedure in $\mathrm{mSv}$ was calculated based on the Portuguese results between 2010 and 2012. The values were compared again with DDM2 countries' results as shown in Fig. 7, and even more so with the values obtained for neighbouring Spain. ${ }^{14}$ In terms of absorbed dose per procedure, the results are similar between Portugal, Spain and European countries, except for myocardium perfusion image with thallium, where the difference is higher than $10 \mathrm{mSv}$ (higher value in Portugal and inexistent in Spain). The dose per procedure of thyroid metastases (after ablation, uptake 0\%) and whole body PET exam also show higher values in Portugal. 


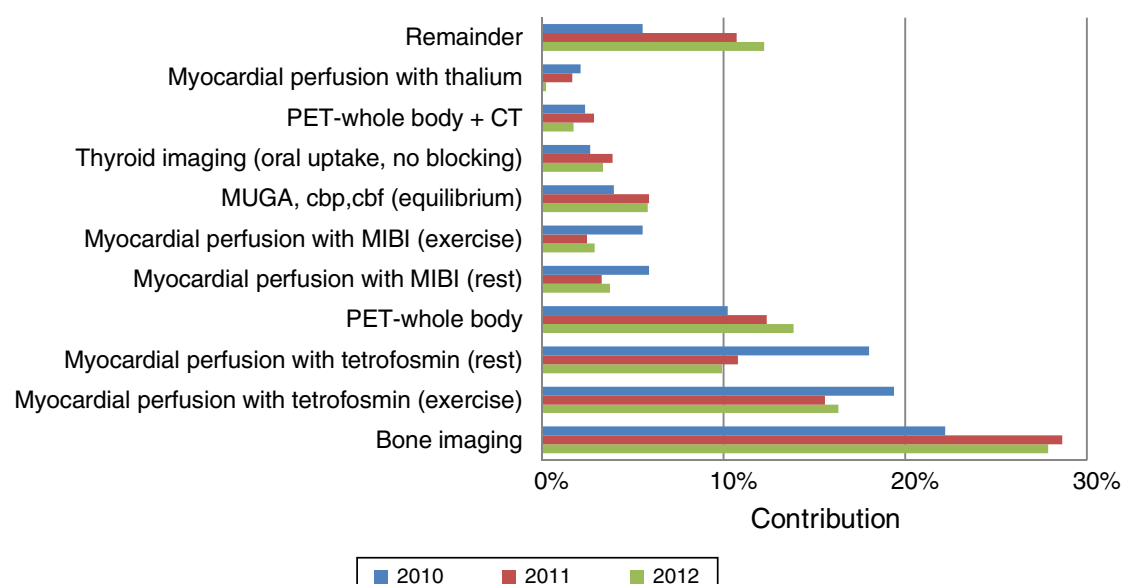

Fig. 5. TOP 10 of 2010 NM exams that contribute (\%) the most to the total collective effective dose of Portuguese population in the years 2010,2011 and 2012.

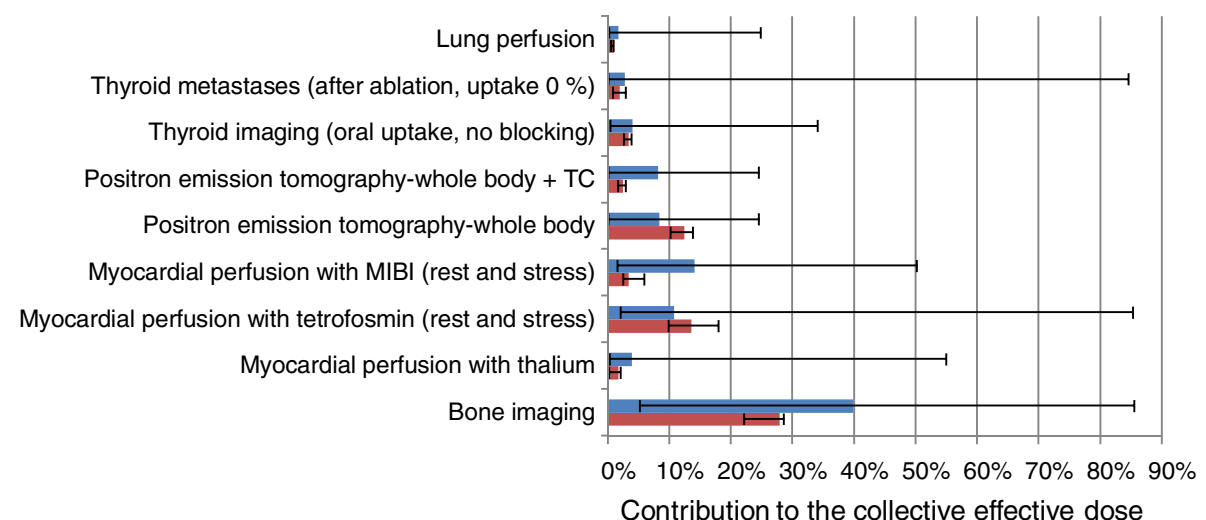

DDM2 countries Portugal

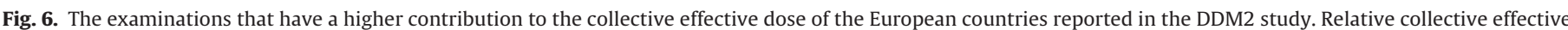
dose for DDM2 countries and Portugal.

\section{Questionnaire}

From the 25 nuclear medicine participant centres, only 12 replied to the survey, although the results given were assumed to be representative of Portuguese NM centre reality. Of the respondent centres, more than $80 \%$ of the NM centres responded to question 1 that they follow the European Association of Nuclear Medicine (EANM) guidelines, ${ }^{15}$ the Society of Nuclear Medicine and
Molecular Imaging (SNMMI) guidelines ${ }^{16}$ and the British Nuclear Medicine Society (BNMS) protocol, ${ }^{17}$ or some form of adaptation. When asked if they will follow Portuguese guidelines in the second question, $80 \%$ responded positively, however some referred they had to compare them with the guidelines they already have and follow for quality assurance. The third question reveals the concern to know if the Portuguese NM centres register the activity administered to each patient or just the protocol values. As a response to

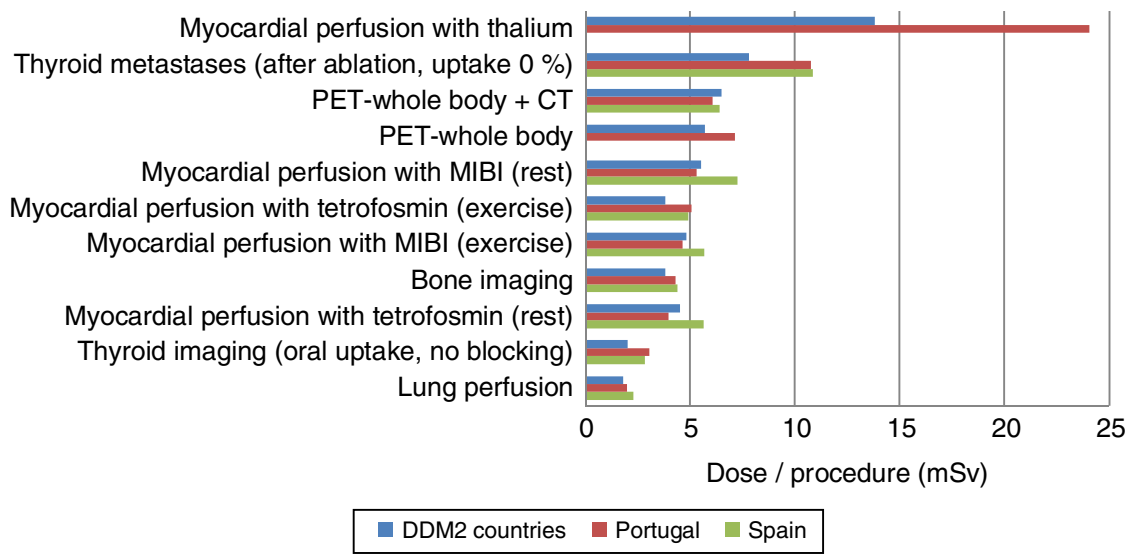

Fig. 7. Average effective dose per NM procedure in $\mathrm{mSv}$ of the DDM2 Countries, Spain and Portugal. 
it, 75\% of the surveyed centres register the activity values for each patient, and the others just save the protocol values. Concerning question 4 , only $25 \%$ (three centres) had the data already separated from paediatric and adult patients and for 33\% (four centres) it was easy to separate the data. In question 5 only three centres of the 12 responded that they can provide the data separated by age and sex.

\section{Discussion}

In 2011 and 2012 it was possible to collect data from more NM centres in Portugal than in 2010. Nevertheless a decrease in the number of NM exams was observed. This was mostly due to a considerable reduction in the number of performed cardiac examinations but also due to a decrease in the bone imaging exams performed. Among the reasons why the number of cardiac exams diminished is due to the implementation of improved techniques for diagnostics (such as echograms) which do not utilize ionizing radiation. Another contributor could be the financial crisis, which may have affected the number of prescribed cardiac exams in the Health care centres. To reinforce this idea, the total number of NM examination performed during the three years, not counting the cardiac and bone examinations, are approximately constant during the three years. The decrease was particularly evident in the myocardial perfusion with tetrofosmin (exercise and rest) and myocardial perfusion with MIBI (exercise and rest) examinations. This explains the reduction in the total annual average collective dose for the year 2011 and 2012, as well as a reduction in the dose per caput for each nuclear medicine, when compared with 2010.

Nonetheless a reduction is observed; cardiac exams continued to be the examination that contributed the most in terms of number of exams performed and total annual dose in 2011 and 2012, although, with a lower percentage compared with 2010. The reduced proportion of cardiac examinations explains the higher relative contribution of the five other groups of examinations in the last two years, compared with the results obtained in 2010 , especially the increase in the percentage of bone imaging and remainder exams performed (Fig. 3). Whole body PET was the exam that contributed more for the high percentage of remainder exams, increasing the percentage in 2011 and 2012. This increment was due to an increase on the number of whole body PET exams performed in Portugal, while de average collective dose was approximately constant. Also, somatostatin receptors imaging examination which had contribution that was low in 2010, but in 2011 and 2012 it showed a high contribution (Fig. 4). This could be explained by a great variability on the average activity administered to the patients for somatostatin receptors imaging among the participant NM centres in Portugal.

The examinations that have a higher contribution to the relative collective effective dose of the European countries reported in DDM2 differ from the Portuguese results, in particular for bone imaging and myocardium perfusion with MIBI (Fig. 6). Nevertheless, a large range is observed in the data compiled in the DDM2 report, in which minimum and maximum values are very different depending on the considered European country. In terms of average effective dose per NM procedure, the results obtained for Portugal are similar with DDM2 reported values, except for myocardial perfusion with thallium. This could be due to less robustness in the available Portuguese data, since this examination is rare in Portugal (Fig. 2), being only performed in three nuclear medicine centres.

The questionnaire was important to characterize the NM centres in Portugal and to identify measures that should be taken in order to standardize the protocols and the way the information is collected in each centre. The survey reveals that the creation of Portuguese guidelines is a possibility and should be developed. The questionnaire was also alert for the fact that $25 \%$ of the surveyed did not register the activity value administered to each patient, which means that some centres sent the protocol activity values, which although are a good approximation to the reality, they might be biased. Question 4 was also essential to understand if the Portuguese healthcare system is prepared to efficiently provide periodic detailed information if needed. More than $50 \%$ could easily provide the data for adult patients only, one centre referred difficulties to separate the data while four said it was impossible to separate. This is a concern because it means that some of the results sent are being influenced by low activity values administered to paediatric patients, thus decreasing estimated values of collective effective dose of Portuguese population calculated in this study. In other European countries, data on the age distribution of patients undergoing nuclear medicine examinations were available. ${ }^{4}$ In order to understand if this study is feasible in Portugal question 5 was asked, however the majority of the centres is not prepared to provide this type of information, since it will be time consuming in some cases and even impossible in others where they do not keep record of the ages of the patients.

\section{Conclusion}

This study is a continuity of DDM2 - Portugal, and provides an estimation of the dose received by Portuguese population in nuclear medicine exams, following the RP 154 methodology. It was possible to compile data from more NM centres in the years 2011 and 2012 compared with the data collected in 2010 . The main nuclear medicine centres in Portugal, which annually perform more examination, participated in this study, allowing us to state that this study will be very representative of the Portuguese reality. The annual average effective dose decreased in 2011 and 2012 due to the reduction of the number of NM exams performed, particularly due to cardiac exams but also due to bone imaging. Nevertheless, these two exams continue to be the most frequent exams and the ones that contributed the most for total population dose. Contact with nuclear medicine centres is required to better understand the decrease of NM exams performed, although financial problems seem to be the reason. The high contribution of neuroendocrine tumours/somatostatin receptors imaging to the annual collective dose in the years 2011 and 2012 is also of great concern, and the reasons will be investigated through direct contact with the healthcare professionals. The Portuguese results of average dose per procedure are similar with the results presented on the Dose Datamed 2 report, with an exception of myocardial perfusion with thallium. The contribution of whole body PET examinations has also increased, and it is thus important to keep track of these values in future evaluations of the annual collective dose. In addition it is important to note that in hybrid techniques such as PET/CT and SPECT/CT, the dose received by the patient will be higher due to the dose received by the $\mathrm{CT}$ exams, which is not taken into account in this study. Improvements are still needed to guarantee that all the centres send the average activity administered to adult patients and can eventually separate activity values between adults and children. It is also expected to expand the participation of NM centres in Portugal to $100 \%$, through the creation of an on-line platform to simplify the data share. Nonetheless, we recommend that all nuclear medicine centres start to organize the data in the DDM2 data format, since it is expected to perform this study periodically, in order to identify trends in the annual effective dose and annual collective dose of Portuguese Population. This will allow for raising awareness in medical professionals, staff and members of the public and for potential dose optimization. In addition, the availability of such data will facilitate the implementation of radiation protection requirements in Portugal. 


\section{Acknowledgements}

The authors thank all the nuclear medicine centres and institutions that supplied data for this work: Cimo - Centro de Imagem Molecular, Hospital de S. João, Hospital Geral de Santo António, Instituto Português de Oncologia Francisco Gentil, EPE - Porto, Instituto Português de Oncologia Francisco Gentil, EPE - Coimbra, Instituto Português de Oncologia Francisco Gentil, EPE - Lisboa, HPP - Medicina Molecular Porto, Hospitais da Universidade de Coimbra, ICNAS - Instituto de Ciências Nucleares Aplicadas à Saúde, DIATON, Faculdade de Medicina da Universidade de Lisboa, Hospital da Força Aérea, Atomedical, Hospital CUF Descobertas, Hospital da Luz, Hospital dos Lusíadas, Fundação Champalimaud, Hospital de Santa Cruz, Centro Oncológico Dr. $\stackrel{a}{a}$ Natália Chaves, Clínica Quadrantes Miraflores, Hospital Beatriz Ângelo, Hospital Garcia de Orta, NuclearMed - Hospital Particular de Almada, Hospital Particular do Algarve, and Quadrantes - Unidade de Radioterapia do Funchal.

\section{References}

1. UNSCEAR Report 2008. Report: 1916 Volume I: sources - report to the General Assembly Scientific. Sources and effects of ionizing radiation. United Nations Scientific Committee on the Effects of Atomic Radiation. United Nations: 2008.

2. UNSCEAR Report 2010. Report of the United Nations Scientific Committee on the effects of atomic radiation. United Nations Scientific Committee on the effects of atomic radiation. United Nations; 2010.
3. European Commission. EU Scientific Seminar 2003 medical overexposures Radiation Protection 149. Directorate-General for Energy and Transport; 2008.

4. European Commission. European Guidance on estimating population doses from medical X-ray. Radiation Protection 154. Directorate-General for Energy and Transport; 2008.

5. Dose Datamed II project. ENER/2010/NUCL/SI2.581237.

6. DDM2 project report on European population dose estimation - draft; 2010.

7. Dose Datamed II; 2013. Webpage. Available at: http://www.ddmed.eu [accessed 31.12.13].

8. Dose Datamed II Portugal; 2013. Webpage. Available at: http://www.itn.pt/ projs/ddm2-portugal/ [accessed 01.01.13]

9. Teles P, Sousa MC, Graciano P, Santos J, Pascoal A, Cardoso G, et al. Estimation of the collective dose in the Portuguese population due to medical procedures in 2010. Radiat Prot Dosim. 2013;154:446-58.

10. ICRP. Radiation dose to patients from radiopharmaceuticals. Ann ICRP. 2001 [ICRP 53].

11. ICRP. Radiation dose to patients from radiopharmaceuticals. Ann ICRP. 1999 [ICRP 80].

12. ICRP. Radiation dose to patients from radiopharmaceuticals. Ann ICRP. 2007 [ICRP 106].

13. Indicadores Sociais Instituto Nacional de Estatistica - Statistics Portugal. 2010.

14. Ruiz-Cruces R, Ramírez ML, Cañete S, Ruiz A, Pérez-Martinez M, Alonso-Farto $\mathrm{J}$, et al. Estimación de las dosis poblacionales en España por procedimientos diagnósticos de radiología y medicina nuclear. Revista de seguridas nuclear y protección radiológica. 2013:21:49-59.

15. European Association of Nuclear Medicine - Guidelines; 2013. Webpage. Available at: http://www.eanm.org/publications/guidelines/index.php?navId=37 [accessed 31.10.13].

16. The Society of Nuclear Medicine and Molecular Imaging - Guidelines: 2013. Webpage. Available at: http://interactive.snm.org/index.cfm?PageID=77 [accessed 31.10.13].

17. BNMS Clinical Guidelines; 2013. Webpage. Available at: http://www.bnms.org. uk/procedures-guidelines/bnms-clinical-guidelines/ [accessed 31.10.13]. 